\title{
Effect of propranolol on acute withdrawal tremor in alcoholic patients
}

\author{
HEIKKI TER ÄV ÄINEN ${ }^{1}$ AND ANDREO LARSEN \\ From the Department of Neurology, University of Helsinki, Helsinki, Finland
}

SYNOPSIS The effect of the $\beta$-adrenergic blocking agent propranolol was tested on positional tremor occurring during acute alcohol withdrawal using a double-blind crossover method and electrical recording of tremor amplitude and frequency. The difference between the effects of propranolol and placebo was not significant.

$\beta$-adrenergic blocking agents such as propranolol have been widely used in clinical practice to treat such diverse disorders of function as hypertension (Zacharias et al., 1972), angina pectoris (Thadani et al., 1973), hyperthyroidism (Malcolm, 1972), thyrotoxic crisis, tachycardia, and cardiac arrhythmias (Parsons and Jewitt, 1967) as well as different forms of tremor (Gilligan et al., 1972; Dupont et al., 1973). Propranolol blocks the $\beta$-adrenergic receptors but also has local anaesthetic, curareand quinidine-like effects (Morales-Aguilera and Vaughan Williams, 1965; Lilleheil and Røed, 1971).

Many symptoms in chronic alcoholics resemble those of increased sympathetic activity. Because propranolol interferes with sympathetic activity its effect has been tested on anxiety and tension symptoms in chronic alcoholic patients (Carlsson and Johansson, 1971; Gallant et al., 1973; Rappolt, 1973) but to our knowledge not much attention has been focused on the tremor occurring during withdrawal of alcohol. We decided therefore to test whether propranolol as a $\beta$-adrenergic blocking agent is of clinical value in the treatment of withdrawal tremor. Even if propranolol abolishes adrenaline aggravated physiological

\footnotetext{
1 Address for correspondence: Heikki Teräväinen, Department of Neurology, University of Helsinki, Haartmaninkatu 4, 00290 Helsinki 29, Finland.

Supported by Signe and Ane Gyllenberg Foundation.

(Accepted 17 February 1976.)
}

tremor (Marsden et al., 1967), it has not appeared to be significantly beneficial in the treatment of tremor in acute withdrawal of alcohol.

\section{METHODS}

PATIENTS The subjects were 28 patients, 22 males and six females, who were being treated behind closed doors with their consent in the Kallio department of the Hesperia Psychiatric Hospital in Helsinki, Finland. A double-blind randomized crossover study was used of propranolol $120 \mathrm{mg}$ / day (Inderal supplied by ICI-Pharma, Finland) against a placebo. Each treatment period was three days. The patients were severe alcoholics of 24-60 years of age (mean 39.4). Ten patients defaulted, six after being treated with propranolol and four after being on placebo, all because of leaving the department and not because of the medication. Consecutive patients were chosen excluding only those with organic neurological or cardiovascular disease or asthma. As a rule the patients had severe symptoms of tension and all had postural tremor. All were treated also with chlormethiazole (Hemineurin) and some patients received diazepam (Valium), which undoubtedly had an undesirable effect on the experimental design. This could not be avoided because of the severe symptoms of tension and anxiety during the withdrawal period. For example, seven of the patients had previously had epileptic attacks during the period of acute alcohol abstinence. However, by the use of a crossover technique, the effects of other drugs on the analysis of the propranolol effect were minimized. 
The tremor was analysed with a fine spring attached to a Plastatzone base, which could be firmly mounted on the dorsum of the patient's hand. The movement of the spring was proportional to the amplitude of the tremor and was measured electrically by using the strain gauge principle with suitable amplification from the oscilloscope. Philips strain gauges type PR 9833K/ 06SE were used. The spring could be adjusted so that the sensitive axis was parallel to the tremor movement.

At first the instrument was so designed that the tip of the spring was attached to one of the patient's fingers with a rigid rod (of piano wire), but this design was found to have no advantage over the spring being freely in the air with a small weight $(1.6 \mathrm{~g})$ attached to its free tip. In the first case the extent of bending of the spring was directly proportional to the amplitude (displacement) of the finger tremor and in the latter case the instrument functioned as an accelerometer with inherent oscillation of $19 \mathrm{~Hz}$. A half time of the fall of consecutive amplitudes produced by oscillation of the spring after a sudden single axial displacement was $50 \mathrm{~ms}$. The coupling constant was determined by the preamplifier and was one second. The total weight of the instrument was 105. $\mathrm{g}$ and it was sensitive enough to record, for example, the invisible physiological tremor of healthy subjects; a mass of $1.0 \mathrm{~g}$ on the tip of the recording spring produced $216 \mathrm{mV}$ amplitude change in the oscilloscope. Both types of recordings gave identical values of the tremor frequency in eight patients so tested with tremor frequencies between 8 and $14 \mathrm{~Hz}$ when controlled with simultaneous electromyographic recording (Figure). The only change in the recordings was difference in the amplitude values obtained and usually the trace was more irregular where the instrument was used as an accelerometer. The recordings were made with the upper arm and fingers at an angle of $90^{\circ}$ to the trunk with the eyes open and the patient seated.

There are other possible sources of error in this type of tremor study. The weight of the instrument placed on the patient's hand presumably increases slightly the amplitude but not the frequency of tremor (Halliday and Redfearn, 1958). Neither this nor the amplitude difference obtained while using the instrument as an accelerometer interferes with comparison of the effects of drugs as long as the same instrument is used and the same group of patients is tested. A more serious source of error is based on the possible variability of the tremor of an individual from time to time as well as possible emotional problems likely to be

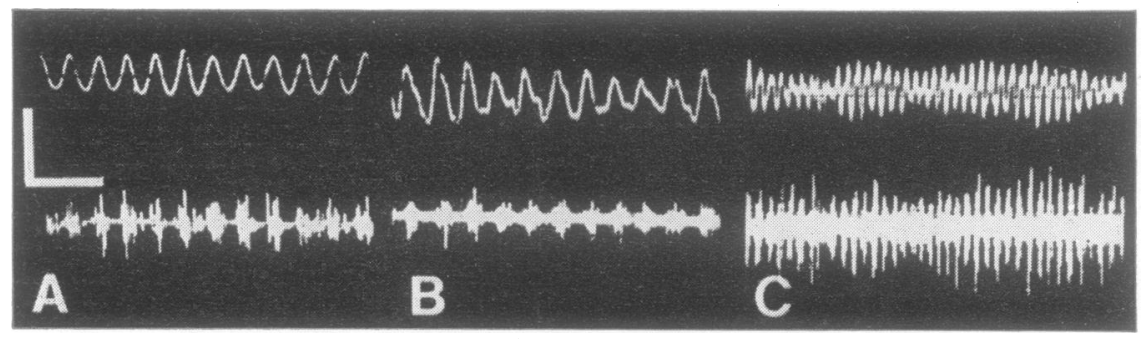

FIGURE Three tremor recordings with simultaneous electromyography of the long finger extensors with surface electrodes. Recording in $A$ was obtained when the spring with strain gauge was fixed to patient's finger and in $B$ from the same patient when the spring was freely in the air (see Methods section). In both cases the instrument gives the same frequency value $(8.5 \mathrm{~Hz})$ as obtained from the EMG recording. This is also illustrated in $C$ with slower sweep and higher tremor frequency of $14 \mathrm{~Hz}$ of another patient. The differences between $A$ and $B$ are smaller amplitude and more irregular trace in $B$ due to properties of the spring. The actual recordings during the tests were made $0.1 \mathrm{~s} \mathrm{~mm}^{-1}$ giving up to 10 seconds' duration for the tremor recording. Faster sweep speeds were also used to obtain the frequency value in the patients with faster tremor frequencies. Amplitude variables measured from the recordings would be in the case of the recording in C: minimum tremor amplitude $=10 \mathrm{mV}$; 'visual mean' amplitude $=20 \mathrm{mV}$; maximum amplitude $=45 \mathrm{mV}$. Time scale is $200 \mathrm{~ms}$ in $A$ and $B$, and $1 \mathrm{~s}$ in C. Voltage scale is $100 \mathrm{mV}$ in $A$ and $50 \mathrm{mV}$ in $B$ and $C$. 
associated with the recording situation. The values recorded during the relatively short period of a day should be interpreted with caution. However, as long as the patients are analysed as a large enough group, the individual fluctuations of the tremor should be statistically irrelevant when the means of a group are concerned.

All values of amplitude in the Results section are expressed in millivolts and as such are relative figures, but comparable with each other since the values of the instrument remained constant. The tremor was recorded from each patient in the evening after they had received the daily dose of either propranolol or placebo. As a rule, the first recording was made on the day after admission and the medication was then begun. The following parameters were measured from a nine seconds trace: (1) frequency of tremor, (2) minimum amplitude (smallest amplitude oscillation), (3) maximum amplitude (largest amplitude oscillation), and (4) 'visual mean' amplitude. 'Visual mean' amplitude is the visually estimated mean value of the tremor amplitude (see Figure). Statistical analysis of the four variables was made by Student's $t$ testing of paired samples.

\section{RESULTS}

After propranolol the mean values of all the amplitude variables-maximum amplitude, minimum amplitude, and 'visual mean' amplitude-were significantly below the values at the start of the trial, but no significant difference was found between the frequency averages of the 18 patients completing the tests (Table 1).

\section{T A B L E 1}

RECORDED MEAN VALUES FOR POSITIONAL TREMOR OF 18 PATIENTS BEFORE AND AFTER 120 MG PROPRANOLOL DAILY FOR THREE DAYS

\begin{tabular}{lccc}
\hline & At start & $\begin{array}{c}\text { After } \\
\text { propranolol }\end{array}$ & $\begin{array}{c}\text { Level of } \\
\text { significance }\end{array}$ \\
\hline Frequency (Hz) & 12.4 & 13.0 & $\mathrm{NS}^{*}$ \\
Maximum amplitude (mV) & 43.1 & 27.5 & $\mathrm{P}<0.01$ \\
Minimum amplitude (mV) & 6.9 & 5.0 & $\mathrm{P}<0.01$ \\
'Visual mean' amplitude (mV) & 23.5 & 15.1 & $\mathrm{P}<0.01$ \\
\hline
\end{tabular}

$* \mathrm{P}>0.05$.

After treatment with placebo the means of maximum amplitude and minimum amplitude and the 'visual mean' amplitude were also significantly lower in the 18 patients completing the tests as compared with the mean values at the start of the trial, but no significant change was observed in the tremor frequency (see Table 2). The maximum amplitude and 'visual mean' amplitude were slightly smaller after propranolol than after placebo, but for all the four variables the differences between the means were not significant (Table 2).

T A B L E 2

RECORDED MEAN VALUES FOR POSITIONAL TREMOR OF 18 PATIENTS BEFORE AND AFTER PLACEBO FOR THREE DAYS

\begin{tabular}{lccc}
\hline & At start & $\begin{array}{c}\text { After } \\
\text { placebo }\end{array}$ & $\begin{array}{c}\text { Level of } \\
\text { significance }\end{array}$ \\
\hline Frequency (Hz) & 11.8 & 12.7 & $\mathrm{NS}$ \\
Maximum amplitude (mV) & 40.9 & 29.8 & $\mathrm{P}<0.02$ \\
Minimum amplitude (mV) & 7.0 & 4.8 & $\mathrm{P}<0.01$ \\
'Visual mean' amplitude (mV) & 22.2 & 17.5 & $\mathrm{P}<0.01$ \\
\hline
\end{tabular}

$* \mathrm{P}>0.05$.

Taking into account all the patients $(\mathrm{N}=28)$ being treated with propranolol $(\mathrm{N}=22)$ and with placebo $(\mathrm{N}=24)$, the maximum amplitude was at the start $39.6 \pm 21.2 \mathrm{mV}$, after propranolol $26.5 \pm 12.0 \mathrm{mV}$, and after placebo $29.8 \pm 11.5 \mathrm{mV}$. The respective values for the minimum amplitude were $6.5 \pm 2.5 \mathrm{mV}, 5.1 \pm$ $1.9 \mathrm{mV}$, and $4.8 \pm 1.4 \mathrm{mV}$, and for "visual mean' amplitude $21.9 \pm 11.4 \mathrm{mV}, 15.1 \pm 5.5$ $\mathrm{mV}$, and $17.5 \pm 6.7 \mathrm{mV}$. The trend is similar to that seen in the 18 patients completing the trial, but again there was no significant difference after propranolol as compared with after placebo. The frequency was at the start $12.1 \pm$ $3.4 \mathrm{~Hz}(\mathrm{~N}=28)$, after propranolol $13.0 \pm 2.8$ $\mathrm{Hz}(\mathrm{N}=22)$, and after placebo $12.8 \pm 2.1 \mathrm{~Hz}$ $(\mathrm{N}=24)$, the differences between the groups being not significant.

T A B L E 3

MEAN VALUES OF RECORDED VARIABLES OF POSITIONAL TREMOR IN 18 CHRONIC ALCOHOLICS AFTER THREE DAYS ON PROPRANOLOL AND PLACEBO

\begin{tabular}{lccc}
\hline & Propranolol & Placebo & $\begin{array}{c}\text { Level of } \\
\text { significance }\end{array}$ \\
\hline Frequency (Hz) & 13.0 & 12.7 & NS* $^{*}$ \\
Maximum amplitude (mV) & 27.5 & 31.8 & NS* $^{*}$ \\
Minimum amplitude (mV) & 5.0 & 4.8 & NS* $^{*}$ \\
'Visual mean' amplitude (mV) & 15.1 & 17.5 & NS* \\
\hline
\end{tabular}

* $\mathrm{P}>0.05$. 
An analysis of variance was also carried out on the values of the four variables obtained on the 18 patients completing the crossover study. This took into account the possible effect of the sequence in which the test substances were given to the patients. No significant difference between the treatment means adjusted for any sequence effect was found in the values of frequency or the different amplitude variables (Table 4).

\section{T A B L E 4}

ADJUSTED MEAN VALUES OF MEASUREMENTS OF POSSIBLE EFFECT OF SEQUENCE IN WHICH TREATMENTS WERE GIVEN TO 18 PATIENTS

\begin{tabular}{lccc}
\hline & Propranolol & Placebo & $\begin{array}{c}\text { Level of } \\
\text { significance }\end{array}$ \\
\hline Frequency (Hz) & 12.5 & 12.7 & NS* \\
Maximum amplitude (mV) & 27.2 & 31.9 & NS* $^{*}$ \\
Minimum amplitude (mV) & 5.0 & 5.0 & NS* $^{*}$ \\
'Visual mean' amplitude (mV) & 15.5 & 18.4 & NS* $^{*}$ \\
\hline
\end{tabular}

* $\mathrm{P}>0.05$.

The frequency of the tremor in alcoholics varied between 7.5 and $18 \mathrm{~Hz}(12.1 \pm 3.4 \mathrm{~Hz}$, mean $\pm S D)$ in all the patients $(\mathrm{N}=28)$. There was a tendency for the tremor to be of lower frequencies $(10.9 \pm 3.5 \mathrm{~Hz})$ in the patients above 40 years of age $(49.5 \pm 5.2$ years, $N=$ $10)$ than in the group of 40 years or less $(33.8$ \pm 5.2 years, $\mathrm{N}=18)(12.8 \pm 3.1 \mathrm{~Hz})$, the difference being not significant, however. Neither were there significant differences in the means of tremor frequencies between the 'more moderate' drinkers treated only once due to alcohol misuse $(12.7 \pm 3.1 \mathrm{~Hz}, \mathrm{~N}=12)$ and the 'more heavy' drinkers $(11.5 \pm 3.8 \mathrm{~Hz}, \mathrm{~N}=$ 12) treated three or more times in the hospital.

The amplitude of the tremor was also analysed as a function of tremor frequency. The difference between the amplitude means of the patients with frequencies below $10 \mathrm{~Hz}(8.9 \pm$ $1.1 \mathrm{~Hz}, \mathrm{~N}=11$ ) compared with those above $10 \mathrm{~Hz}(14.2 \pm 2.6 \mathrm{~Hz}, \mathrm{~N}=17)$ was not significant in any of the amplitude variables. For example, the 'visual mean' amplitude was $22.0 \pm 14.9 \mathrm{mV}$ in the frequency group $10 \mathrm{~Hz}$ or less and $21.9 \pm 8.9 \mathrm{mV}$ in the group above $10 \mathrm{~Hz}$.

\section{DISCUSSION}

The anti-tremor effect of beta-adrenergic blocking agents such as propranolol has been known from animal experiments (Sharma, 1970; Sharma et al., 1971; Watanabe et al., 1971; Leslie et al., 1972) and it is also effective in man in the tremor of Parkinsonism (Owen and Marsden, 1965; Gilligan et al., 1972), the essential tremor (Gilligan et al., 1972; Pakkenberg, 1972 and others, see Dupont et al., 1973; Sevitt, 1974) and other forms of tremor (Sevitt, 1971; Kirk et al., 1972) including the tremor of anxiety and thyrotoxicosis (Marsden et al., 1967). We undertook the test with the expectation that propranolol would have a beneficial effect on the tremor during acute alcohol withdrawal. This did not occur. The central mechanisms in the acute phase may be of importance in producing the withdrawal tremor, on which propranolol is ineffective. Indeed, it has been shown that propranolol aggravateso withdrawal seizures in alcohol dependent mice (Goldstein, 1973).

Several methods have been presented in the literature for quantitative recording of tremor. The principle of using a light source in the beam of which the patient's hand should be kept (Cooper et al., 1957; Fish, 1964) and those. based on electromagnetic detectors (Jasper and Andrews, 1938; Friedlander, 1956), as well as those where piezoelectric change of titanate ceramic transducers are used (Rushworth and Willison, 1960), have the disadvantage that the patient must hold his hand during the recording in a previously specified area-for example, within a beam of light or on a disc. Similar limitation is involved if the strain gauge itself (Tuttle et al., 1951) upon which the patient's hand has to rest is supported or if the patient has to hold a stylus in a hole (Karkalas et al., 1972).

Marshall and Walsh (1956) and Cowell et al. (1965) have used a valve sensitive to acceleration which is free of positional problems like the present method. Both methods seem to be suitable for recording quantitatively both the relative amplitude and the frequency of tremor. With the present instrument the patient can move freely during the recording. The tremor at rest-for example, arm hanging 
freely down-and the positional tremor as well as the tremor during movement can be measured quantitatively. The instrument is also easy to construct and adjust and is inexpensive.

The tremor in alcoholics has previously been recorded objectively. Friedlander (1956) used a magnetic field technique which he said resulted in inaccuracies in the amplitude measurement. He reported that the frequency pattern of 25 alcoholics did not differ significantly from that of the normal population, although the amplitudes tended to be larger. Carrie (1965) used a strain gauge technique against a constant load on 20 patients and reported a frequency pattern resembling that of the control medical staff (up to $12 \mathrm{~Hz}$ ) but of larger amplitude at $7-9 \mathrm{~Hz}$. We found a more extended frequency pattern from 7 to $18 \mathrm{~Hz}$ and no significant amplitude differences between the lower frequency group ( $10 \mathrm{~Hz}$ or less) and that with faster frequencies (above $10 \mathrm{~Hz}$ ). We also found that the mean value of the tremor in alcoholics was $12.1 \mathrm{~Hz}$, which is higher than the mean physiological tremor of about $10 \mathrm{~Hz}$ (Marshall, 1968) and higher than that we have found in essential tremor $(10 \mathrm{~Hz})$ in 21 patients with a mean age of 41.2 years (Teräväinen, Fogelholm and Larsen, to be published). A tendency to faster frequencies in alcoholics has also been reported by Friedlander (1956). When comparing the results of different workers one must keep in mind that our patients were very heavy drinkers with visible tremor of 'moderate to large' amplitude, whereas in Friedlander's group about $50 \%$ (13 patients) had no visible tremor.

\section{REFFRENCES}

Carlsson. C., and Johansson, T. (1971). The psychological effects of propranolol in the abstinence phase of chronic alcoholics. British Journal of Psychiatry, 119, 605-606.

Carrie, J. R. G. (1965). Finger tremor in alcoholic patients. Journal of Neurology. Neurosurgery, and Psychiatry. 28, 529-532.

Cooper, J. D., Halliday, A. M., and Redfearn. J. W. T. (1957). Apparatus for the study of human tremor and stretch reflexes. Electroencephalography and Clinical Neurophysiology, 9, 546-550.

Cowell, T. K., Marsden, C. D., and Owen, D. A. L.
(1965). Objective measurement of parkinsonian tremor. Lancet, 2, 1278-1279.

Dupont, E., Hansen, H. L., and Dalby, M. A. (1973). Treatment of benign essential tremor with propranolol. Acta Neurologica Scandinavica, 49, 7584.

Fish. S. (1964). A novel method of recording tremor. American Journal of Medical Sciences, 248, 415418.

Friedlander, W. J. (1956). Characteristics of postural tremor in normal and in various abnormal states. Neurology (Minneap.), 6, 716-724.

Gallant, D. M.. Swanson, W. C., and GuerreroFigueroa. R. (1973). A controlled evaluation of propranolol in chronic alcoholic patients presenting the symptomatology of anxiety and tension. Journal of Clinical Pharmacology and New Drugs, 13, 41-43.

Gilligan, B. S.. Veale, J. L., and Wodak (1972). Propranolol in the treatment of tremor. Medical Journal of Australia. 59, 320-322.

Goldstein, D. B. (1973). Alcohol withdrawal reactions in mice. Effects of drugs that modify neurotransmission. Journal of Pharmacology and Experimental Therapeutics, 186, 1-9.

Halliday, A. M., and Redfearn, J. W. T. (1958). Finger tremor in tabetic patients and its bearing on the mechanism producing the rhythm of physiological tremor. Journal of Neurology, Neurosurgery, and Psychiatry, 21, 101-108.

Jasper, H. H., and Andrews, H. L. (1938). Brain potentials and voluntary muscle activity in man. Journal of Neurophysiology, 1, 87-100.

Karkalas, Y.. Smith. N., Zabik. J. P., and Harbans, L. (1972). Objective measurement of extrapyramidal symptoms through forearm tremors in humans by automatic recording. Clinical Toxicology, 5, 381-385.

Kirk, L., Baastrup. P. C., and Schou, M. (1972). Propranolol and lithium-induced tremor. Lancet, 1, 839.

Leslie. G. B.. Hayman. D. G.. Ireson, J. D.. and Smith. S. (1972). The effects of some beta adrenergic blocking agents on the central and peripheral actions of tremorine and oxytremorine. Archives Internationales de Pharmacodynamie et de Thérapie. 197, 108-111.

Lilleheil, G., and Røed, A. (1971). Antitetanic effect of propranolol on mammalian motor-nerve and skeletal muscle, and combined action of propranolol and neostigmine on the neuromuscular transmission. Archives Internationales de Pharmacodynamie et de Thérapie, 194, 129-140.

Malcolm, J. (1972). Adrenergic beta receptors inhibition and hyperthyroidism. Acta Cardiologica, suppl., 2, 3(17-326.

Marsden, C. D., Foley, T. H., Owen, D. A. L., and 
McAllister, R. G. (1967). Peripheral $\beta$-adrenergic receptors concerned with tremor. Clinical Sciences, 33, 53-65.

Marshall, J. (1968). Handbook of Clinical Neurology, vol. 6, pp. 809-825. Edited by P. J. Vinken and G. W. Bruyn. North-Holland: Amsterdam.

Marshall, J., and Walsh, E. G. (1956). Physiological tremor. Journal of Neurology, Neurosurgery, and Psychiatry, 19, 260-267.

Morales-Aguilera, A., and Vaughan Williams, E. M. (1965). The effects on cardiac muscle of $\beta$-receptor antagonists in relation to their activity as local anaesthetics. British Journal of Pharmacology, 24, 322-338.

Owen, D. A. L., and Marsden, C. D. (1965). Effect of adrenergic $\beta$-blockade on parkinsonian tremor. Lancet, 2, 1259-1262.

Pakkenberg, H. (1972). Propranolol in essential tremor. Lancet, 1, 633.

Parsons, V., and Jewitt, D. (1967). Beta-adrenergic blockade in the management of acute thyrotoxic crisis, tachycardia and arrythmias. Postgraduate Medical Journal, 43, 756-764.

Rappolt, R. I. (1973). Treatment of ethanol withdrawal employing a beta-adrenergic blocking agent (propranolol). Clinical Toxicology, 6, 293294.

Rushworth, G., and Willison, R. (1960). A method of recording small movements. Lancet, 1, 632-633.

Sevitt, I. (1971). The effect of adrenergic beta-receptor blocking drugs on tremor. Practitioner, 207, 677-678.
Sevitt, I. (1974). A comparison of propranolol and benzhexol in essential tremor. Practitioner, 213, 91-96.

Sharma, P. L. (1970). Mechanism of antitremorine activity of adrenergic beta-receptor antagonists in the rat. Quarterly Journal of Experimental Physiology, 55, 202-206.

Sharma, P. L., Singh, G. B., and Dhawan, B. N. (1971). Effect of beta-adrenergic blockage on tremorine tremors in mice. Japanese Journal of Pharmacology, 21, 675-677.

Thadani, U., Sharma, B., Meeran, M. K., Majid, P. A., Whitaker, W. W., and Taylor, S. H. (1973). Comparison of adrenergic beta-receptors antagonists in angina pectoris. British Medical Journal, 1, 138-146.

Tuttle, W. W., Janney, C. D., Wilkerson, D., Jr., and Imig, C. J. (1951). Effect of exercises of graded intensity on neuromuscular tremor as measured by a strain gauge technique. Journal of Applied Physiology, 3, 732-735.

Watanabe, H., Munakata, H., Chen, S. C., and Kasuya. (1971). Effect of L-dopa, adrenergic $\beta$ blockers and anticholinergic agents on the tremorine tremor on mice. Archives Internationales de Pharmaco-dynamie et de Thérapie, 193, 372-380.

Zacharias, F. K., Cowen, K. J., Prestt, J., and Wall, B.-G. (1972). Propranolol in hypertension: A study of long-term therapy, 1964-1970. American Heart Journal, 83, 755-761. 